\title{
Developing program objectives in data analytic field of study using three frameworks
}

\author{
Azad I. Ali, Indiana University of Pennsylvania, USA, azad.ali@iup.edu \\ David T. Smith, Indiana University of Pennsylvania, USA, david.smith@iup.edu
}

\begin{abstract}
This paper presents a methodology and results in developing program as well as course objectives to be included in curriculum proposals. This study provide a literature review and uses steps of keyword indexing, thematic analysis, as well as the popular Bloom's taxonomy field of text in effort to phrase program objectives that follow standards set for this purpose. A set of program objectives for a program in Data Analytics derived by this methodology is presented in the conclusions.
\end{abstract}

Keywords: Data analytic, business data analytics, big data analytics, and data science.

\section{Introduction}

"The era of big data and analytics is upon us and is changing the world dramatically. The field of Information Systems should be at the forefront of understanding and interpreting the impact of both technologies and management so as to lead the efforts of business research in the big data era. We need to prepare ourselves and our students for this changing world of business." (Baesens, Bapna, Marsden, Vanthienen, \& Zhao, 2016, p. 807)

Indeed the field of data analytics has been growing fast - there is increasing need for skills and expertise in this field, while the pressure has been mounting on academic programs to prepare their students for this vast changing field of study (Rahm, 2016). Many departments have responded to this demand and have prepared programs for data analytics (Mills, Chudabo, \& Olsen, 2016), while others may still be working on developing data analytics programs. One of the departments that is taking preparatory steps to develop a program in data analytics is an Information Systems department at a university located in Western Pennsylvania.

Developing any new program of study requires introducing program objectives that guide the development of the program's curriculum including the development of course syllabi. New programs and syllabi may also go through an institution's curriculum procedures to be formally included in the university program offerings. This paper focuses on the first steps to develop these program objectives for a program in data analytics. Theses program objectives will set the stage for the directions of the new program and further guide the development of courses within the program. 
To achieve that goal, this paper outlines the following steps:

1. It first reviews the literature regarding the data analytics as a field of study

2. It identifies keywords that are specific to this fields of study

3. It combines the keywords into themes to be used in the program objectives

4. The paper then using Bloom's Taxonomy phrases the themes into sentences that represent the program objectives for a program in data analytics.

Figure 1 depicts the steps that we followed in this paper.

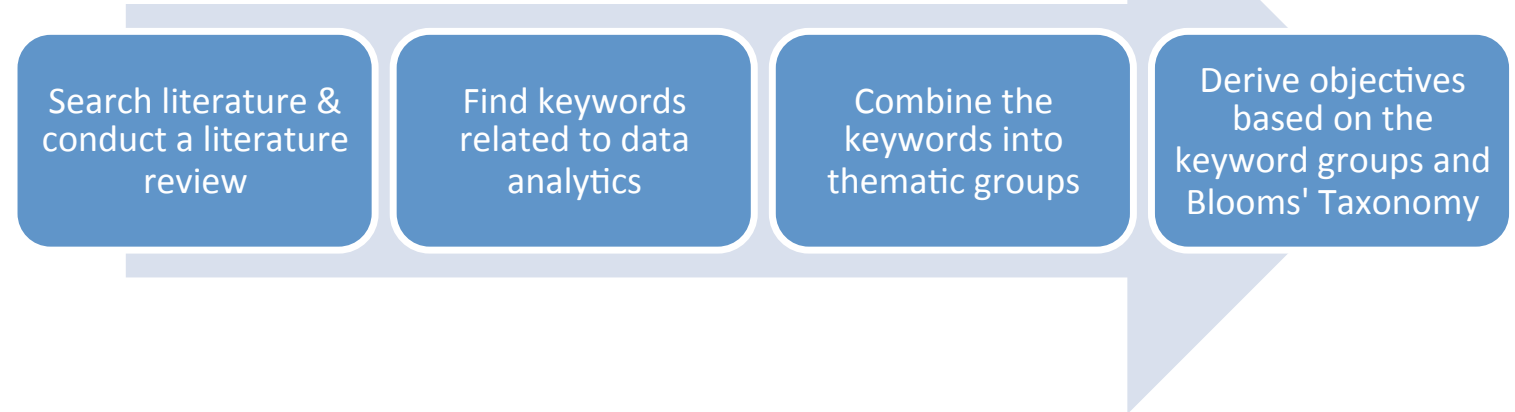

Figure 1. Steps Used in Developing Program Objectives

\section{Research Methodology}

In this section, we present the methodology we used to derive program objectives for the field of data analytics. Our methodology begins with a literature review of the field. From the literature review we identify keywords using "Keyword Indexing". Subsequently, the keywords are grouped into themes by applying "thematic analysis". Lastly, program objectives are derived using "Blooms taxonomy". Figure 2 shows the application of theses frameworks within the steps of this study. A further discussion of each framework is presented in this section.

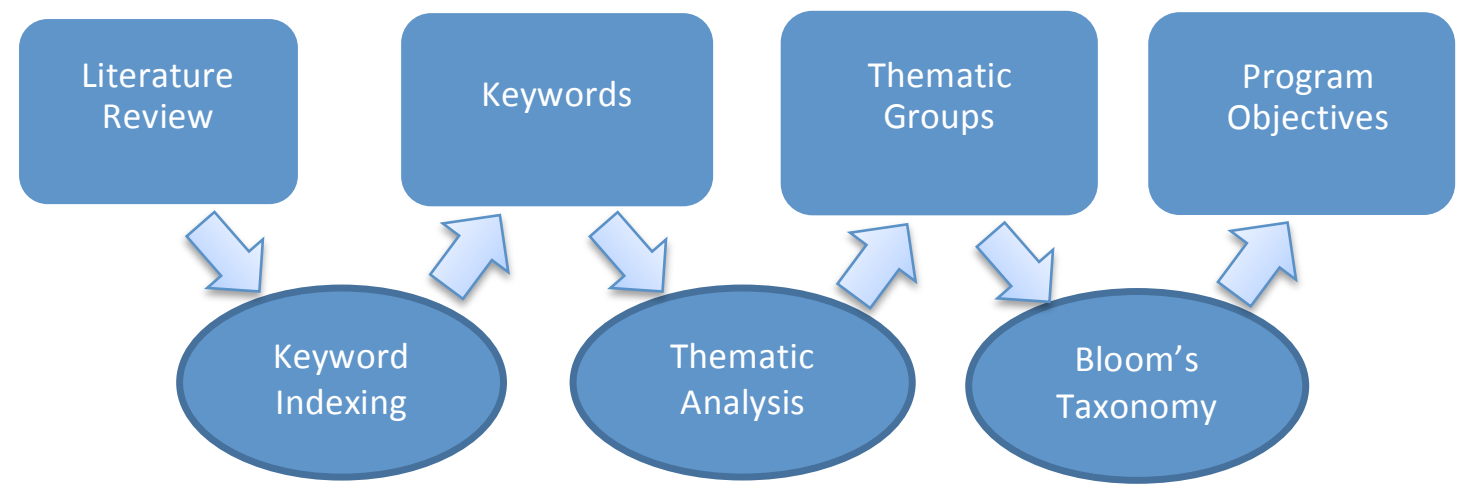

Figure 2. Three Frameworks Used in This Study 


\section{Keywords Indexing}

Keyword indexing is a technique widely used in different fields of study and in technological searches (in particular on the web). Ali and Kohun (2007) used it to identify keywords used to find a pattern in reasons for doctoral student attrition. Sobhi and Son (2010) advocated the use of keywords in studying the job trends in the industry. Smith and Ali (2014) used it to find patterns of jobs to group searches for particular jobs in Information Technology (IT).

The basic steps involved in keyword indexing start by reading through segments of text to identify keywords of the subject. Identified keywords are added to a list for consideration in the next step. In this study, we include a keyword for consideration if it "stands out" in the text. It could be a name of specific technology, method/process/technique for the storage/processing/output of data, or it describes specifics to the field of data analytics.

\section{Thematic Analysis (or Thematic Mapping)}

Clarke and Braun (2013) defined thematic analysis as "a method for identifying and analyzing patterns in qualitative data" (p. 120) and identified six phases of thematic analysis:

- Familiarization with the data

- Coding

- Searching for themes

- Reviewing themes

- Defining and naming themes

- Writing up

The main purpose of thematic analysis is to group together keywords, ideas, concepts and others to make it easier to manage the situation. In other words, instead of being overwhelmed with numerous keywords, these keywords can be grouped together based on some kind of similar characteristics or based on certain classifications. These groups can then be explained as one unit that makes it easier to discuss and draw conclusion on each group as oppose to a diverse larger set of smaller discussions. Furthermore, identifying groups will aide in the formulation of the subject component of a program objective. The subject component is explained in the following section.

\section{Bloom's Taxonomy}

Bloom's Taxonomy or The Taxonomy of Educational Objectives is "a framework for classifying statements of what we expect or intend students to learn as a result of instruction" (Krathwohl, 2002 , p. 212). It is widely used in academia to establish course objectives as the development of course syllabus go through curriculum process approvals. Krathwobl (2002) explained that a statement of a course objective in Bloom's taxonomy is constructed from four components: object, verb, keyword, and subject. For example, Table 1 shows the components used to construct the objective: "The student shall be able to remember the law of supply and demand in economics". 
Table 1. Example of a course objective

\begin{tabular}{|l|l|l|l|}
\hline Object & Verb & Keyword & Subject \\
\hline The student & Shall be able to remember & Law of supply and demand & In economics \\
\hline
\end{tabular}

Krathwohl (2002) further suggested that most institutions omit from an objective sentence the first column (the object) listed in Table 1. In our study, we followed this suggestion and omitted "The Student" from listing the objectives of the program. Thus, the program objectives that we developed in this study will start with a verb, followed by a keyword and then the subject.

The intent of keyword component of a program objective as explained by Krathwobl (2002) is not necessarily the keywords of resulting from step one of our methodology. However, we note that the keywords and thematically groups of our steps one and two can be used in the formulation of keyword and subject of a program objective. The subject may and will often be one of the identified thematic groups. It may also be one of the keywords in our final list. The keyword of the program objective may be one of the final list of keywords or it could be one of the keywords within the thematic group where the keyword appears to be serving as a major characteristic of a theme. Given these observations we formulate program objectives by composing the objective's keyword and subject from our list of keywords, and thematic groups and selecting a verb from Bloom's Taxonomy which best reflects the level of depth a topic is to be covered in our program, all of which is based on our determination and judgment. Figure 3 below shows the development process in formulating a program objective.

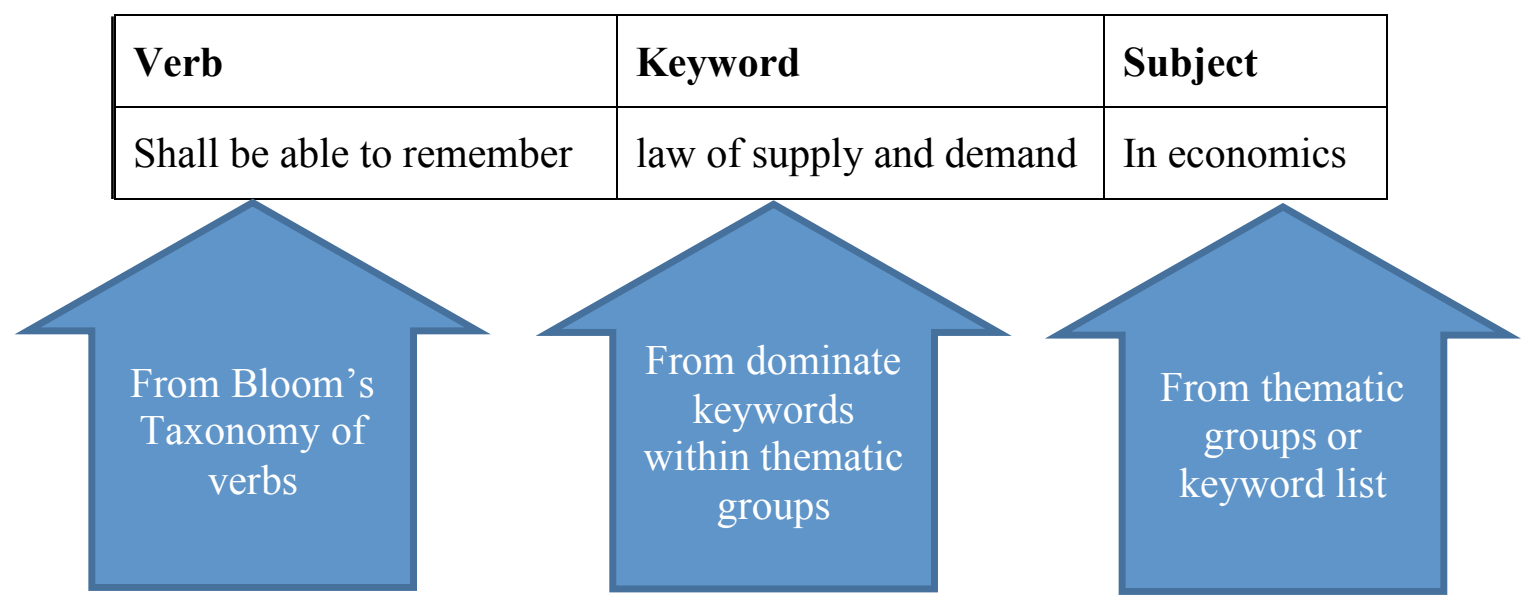

Figure 3. Construction of a Program Objective

\section{Literature Review - The Era of Data Analytics}

The field of "data analytics" is relatively recent area of study and different factors have contributed to its development. Chen, Chiang, and Storey (2012) explained that the field of data analytics started to emerge in the late 1990s for two reasons: 
- Data became abundant and inexpensive

- The recognition that there is a value that can be gained from understanding the large volume of data extracted from different sources

Ong (2016) clarified that due to the mass increase of structured and unstructured sources of data, new technical solutions and managerial approaches were needed to handle the volume of data. As technical solutions and managerial approaches were developed, new programs emerged to teach these solutions and approaches (Rahm, 2016).

Chen et al. (2012) predicted that this field of study is on its way to significantly grow as the demands increase for experts who can understand how to extract meaning from the vast volume of data. Thus, the field of data analytics started to appear in academic programs in a variety of names. The most common names of programs that we found in our research include the following:

- Big data analytics

- Business data analytics

- Business intelligence and analytics (BI\&A)

Although the program appears under different names, this paper addresses all the names under one category of "data analytics" program. Thus, the discussion in this paper focuses on these programs as one connecting field of study. Presented in the following sections is our literature review of data analytics as an overview, as related to the input, processing, and output stages, and other issues.

\section{Data Analytics Overview}

Patel, Sundararajan, Marangos, and Zimmers (2016) described the development of data analytics as a field of study as follows:

- Historical and operational data may show significant undiscovered trends

- These trends could reveal additional opportunities for business

- The existing technologies that existed before the appearance of "data analytics" field of study were not helpful in revealing these additional opportunities

- There was a need to develop technologies that reveal these future opportunities and thus programs that teach these technologies.

Lim, Chen, and Chen (2013) echoed that the field of data analytics gained traction among IT practitioners and researchers in the 1990s in reference to the technologies, systems and practices that help analyze data for enterprises to better understand their businesses and markets. Benjamins (2014), on the other hand, noted that the growth in data volumes, the rise of unstructured and semi-structured data, along with the desire to extract more valuable business insights are main reasons that led to increase use of data analytics as a field of study. Wixom et al. (2011) took it a step further and noted that current trends suggest that academia may be behind in delivering effective data analytics programs. Wixom, Aruyachanrdra, Goul, Gray, and Kulkarni (2014) suggested further that Information Systems (IS) programs take the brunt of responsibility for keeping with the market in this regards. 
The most notable reference point when talking about introducing data analytics field of study is the 4Vs effect factors (Baesens et al., 2016; Bhadani \& Jothimani, 2016; Gupta, Goul, \& Dinter, 2015; McCafee \& Brynjolfsson, 2012; Rahm, 2016). The 4Vs came in reference to four features that characterizes the development of data analytics, all which start with the letter $\mathrm{V}$ and they are: Volume, Variety, Velocity, and Value. An added and crucial note here is what mentioned by Davenport (2006) when explained that data analytic transformed technology from a supporting tool to a strategic weapon.

\section{Input in Data Analytics}

The advances of technology (including social media, Internet of Things (IoT), etc.) caused the following additions to existing technologies used for data input:

- Led to creating additional data sources

- Substantially added to the volume of data entered into computing resources

- Further increased the methods by which data are transmitted and stored for further processing

Choi, Chun, and Dalsang (2017) explained that the size of digital growth is over $40 \%$ a year and that the expected growth in data entry will double every two years, generating a continuous demand for more resources for data input. Furthermore, this is compounded by additional of sources of data. For example, McAfee, Brynjolfsson, Davenport, Patil, \& Barton (2012) included Facebook, Twitter, and Smart Phones, as sources for input.

Assunção, Calheiros, Bianchi, Netto, and Buyya, (2015) identified a few sources of data from tweets, blogs, product evaluations and data from social networks. Likewise Choi, Chun, and Dalsang (2017) discussed sources for big data such as Internet based web, emails, social network services, Twitter, Facebook, YouTube, Amazon, etc. Hashem, Yaqoob, Anuar, Mokhtar, and Gani (2015) explained that the continuous increase in the volume and detail of data captured by organizations, such as the rise of social media, IoT, and multimedia has produced an overwhelming flow of data in either structured or unstructured format. Bhadani and Jothimani (2016) discussed other sources of data analytics like financial, healthcare, Internet of Things, media/entertainment, social media, telecommunications, transportation, video surveillance, and others.

This increase of volume and resources of data led to another issue that was not dealt with in previous data input technologies and methods. That is, the data that may not be in a structured format used by previous data methods to characterize data. Today, data may be entered in any of the three formats: structures, semi-structured and unstructured. In addition to the above, data may come from devices beyond traditional computing, for example, data from devices connected to the Internet, i.e. IoT sources. Such data is not entered into computing devices to be processed (Mahapatra, Gerostathopoulos, \& Prehofer, 2016), but rather is 'extracted' from these sources and then saved into data depositories to be transmitted for further processing (Cuzzocrea, Song, \& Davis, 2011). Phillips-Wren, Iyer, Kulkarni, and Ariyachandra (2015) summarized this by explaining that data entry into data analytics includes the steps of data extraction, transformation, and loading (ETL). 


\section{Processing in Data Analytics}

The increase in the volume of data and in different formats made most existing technologies incapable of processing the large data volume. As a result, new technologies encompassing new procedures, new techniques, and new hardware were needed. Furthermore, time to process the data is a major consideration in the era of data analytics. At the hardware level, the existing 'one server' per company proved to be insufficient to process large data volume. Instead, processing was handled on multiple servers and data files were not kept in the 'structured only' format that was prevalent in the past (Fowler, 2006). In regards to techniques for processing, Bhadani and Jothimani (2016) suggested to explore practices such as applying rule-based systems, pattern mining, decision trees, and other mining techniques to the large volume data that characterizes data analytics. Similarly, processing of the new volume of data needs to account for processing time. Chiang, Goes, and Stohr (2012) classified data processing according to required turnaround time, which can be divided into three categories: (a) batch, (b) near time, and (c) real-time. Likewise, Russom (2011) classified data processing in terms of four categories: (a) batch, (b) near time, (c) real time, and (d) streams of data.

In regards to the technologies that handle this new volume of data, several new technologies were developed, most notable is the Hadoop performance platform and the map reduce model (Khan, Huang, Taylor, Ashton, \& Khan, 2017). Fowler, Walker, Williams, and McDonald (2015) noted that other technologies involved in the selection within the context of processing data in data analytics, like NOSQL database ('non SQL' or 'non relational') for semi-structured data. For example, CouchDB ${ }^{\mathrm{TM}}$ that is often used for processing NOSQL data sets. Data analytics processing may include additional dimensions such as visualization, exploration, simulation, and optimization (Ong, 2016). Likewise, Watson (2014) noted data analytics processing for executive information systems, online analytical processing (OLAP), and dashboard/score board.

\section{Output in Data Analytics}

To provide a realizable value from data analytics the output must extend beyond reports and listings in order to aid management in: decision making, enhancing business performance, and increasing business opportunities. This includes charts, graphs, summary reports, and dashboard/scoreboard. For example, Assunção et al. (2015) suggested that the availability of data collected from consumer surveys coupled with private information collected through Internet searches could open a wide range of possibilities for business to better understand the needs of their customers. Polanka (2013) noted that output from data analytics might include pattern attitudes, market trends, and cost analysis. Gupta, Goul, and Dinter (2015) took this a step further and suggested that output generated from data analytics can be used in the Executive Information System (EIS). Other uses of data analytic output include:

- Data segmentation and clustering (Khan et al., 2017)

- Classification and regression analysis (Baesens et al., 2016)

- Data mining analysis, hidden trends, and guided decision making (Patel et al., 2016)

- Business bench mark performance management (Chen et al., 2012)

- Prediction analysis for structured data (Gandomi \& Haider, 2014)

- Pattern recognition (Khan et al., 2017) 
- Predictive analysis (Sitton, 2016)

Data analytics field can also be merged in the emerging fields of cloud computing. Cuzzocrea et al. (2011) noted about the design and the use of Data-as-a-Service (DaaS) and Infrastructure-asa-service (IaaS) as applications for cloud computing typically uses different data analytic techniques.

\section{Other Issues in Data Analytics}

In addition to the three main stages, our literature review found several important topics that span data analytics. For example, Gupta et al. (2015) talked about the ethical issues, security issues, privacy issues, and future emerging issues. Verma and Voida (2016) explained some of the drawbacks, errors, and biases from the use of data analytic programs and the resulting influences on organizations. Verma (2016) also talked about the epistemological biases that could be generated from data analytics. Royster (2013) explained that data entered from various resources could generate a large volume of output that may contain errors. To address this problem an additional stage of "scrubbing" maybe needed to remove errors and limit excess information before final output.

\section{Discussion and Findings}

In this section, we describe our findings from sifting through the literature review and going through the different stages of input, processing and output. As noted earlier, we consider keywords when they "stand out" among the words.

\section{Stage 1: Identifying Keywords}

Input stage keywords: Internet of Things, Facebook, Twitter, Smart Phones, Tweets, blogs, product evaluations, structured data, unstructured data, semi-structured data, and data extraction.

Processing stage keywords: One server, multiple servers, rules-based, pattern mining, decision trees, structured only, rule based, batch, near time, real-time, Hadoop performance, Map reduce model, NoSQL, CouchDB ${ }^{\mathrm{TM}}$, scientific applications, medical information systems, e-government applications, extraction-transformation loading (ETL), and process from low-level data.

Output stage keywords: Chart and graph analysis, data segmentation, classification and regression analysis, data mining analysis, hidden trends, guided decision making, business bench mark performance management, prediction analysis for structured data, pattern recognition, traffic management through data analysis, and predictive analysis.

Keywords from other issues in Data Analytic: ethical issues, security issues, privacy concerns, future emerging issues, epistemological biases, errors in data analytic, and scrubbing of data.

\section{Stage 2: Grouping Keywords}

The next step was to group the keywords under themes in preparation to derive program objectives. In doing so, specific products, techniques, processes, etc. are identified in broader more inclusive terms. Table 2 shows the different themes that we derived from our list of keywords. 
Table 2: Grouping of Keyword into Themes for Data Analytics

\begin{tabular}{|l|l|}
\hline Keyword & Theme \\
\hline 4V (Volume, Variety, Velocity and Value) & Dimensions of data analytic \\
\hline $\begin{array}{l}\text { Tweets, blogs, YouTube, IoT, product evaluations and data } \\
\text { from social networks }\end{array}$ & Data sources for data analytic \\
\hline Structured, semi structured and unstructured & Categories of data \\
\hline Extracting, entering, scrubbing & Data entry and validation \\
\hline Rule-based system, pattern mining, decision trees & Data processing techniques \\
\hline Visualization, exploration, simulation, and optimization & Data presentation methods \\
\hline $\begin{array}{l}\text { Executive information system (EIS), guides decision } \\
\text { making, }\end{array}$ & Managerial uses \\
\hline Hadoop, map reduce, CouchDB ${ }^{\text {TM }}$ & Processing technologies \\
\hline $\begin{array}{l}\text { Data segmentation \& clustering, regression analysis, } \\
\text { Business bench mark performance management }\end{array}$ & Data analysis techniques \\
\hline $\begin{array}{l}\text { Pattern recognition, predictive analysis, market trends, and } \\
\text { cost analysis }\end{array}$ & Data analysis methods \\
\hline Drawback, errors and biases & Shortcoming \\
\hline Ethical issues and security issues & Ethical and security issues \\
\hline
\end{tabular}

\section{Stage 3: Selecting Verbs from Bloom's Taxonomy}

In our selection for verbs to complete our objectives, we relied on verbs suggested in Bloom's Taxanomy. Bloom's taxonomy suggests different verbs that can be included in course or program objectives. The benefit of these words listed in the taxonomy is that they are measurable. That is, the outcome from these verbs can be measured and thus achievement can be gauged whether or not the objective is met. Bloom's taxonomy is divided into a hierarchy that provides measurement according to levels of thinking of complexity. Verbs listed at the higher levels (e.g. design, appraise, \& construct) in the hierarchy present more complex and more indepth understanding. While verbs listed in the lower level (e.g. define, describe, \& identify) require less depth coverage and lesser level of knowledge. Our goal was to diversify the inclusion of verbs in our objectives to avoid the use of redundant words and to include different levels of coverage as required and deemed appropriate for the program. For coverage that requires the learning of technologies, we deemed that higher level of coverage is helpful to the students. For other subjects like "security" and "ethical values" they requires less coverage because we cover similar topics in other courses.

\section{Resulting List of Objectives}

Based on the analysis of the previous sections and our literature review, we formulated the program objectives for a data analytics field of study as follows:

- Discuss the dimensions of data analytics 
- Identify data sources that contributed to data analytics field

- Compare and contrast the different categories of data sources

- Employ various methods for data entry, validation and correction

- Compare and contrast the different data processing techniques

- Prepare different methods of output presentation in data analytics

- Assess the managerial uses of output from data analytics

- Apply appropriate technologies in the processing of data analytics

- Appraise the different techniques used in data analytics

- Design means for uses of data analytic methods

- Evaluate the shortcoming of data analytics field

- Articulate the ethical and security concerns in data analytics

\section{Summary}

In this paper, we presented a methodology to derive program objectives. Our methodology begins with a literature search and then uses keyword indexing to identify a set of keywords. The keywords are then grouped into themes by applying "thematic analysis." Lastly, program objectives are derived from the keywords and themes by applying Blooms taxonomy. We applied our methodology to the field of data analytics with the goal of developing a set of program objectives for a new program at our university. We found our methodology to be effective and successful in developing program objectives for proposal of a program in data analytics. Given this success, we believe our methodology to be sound and we recommend its use for development of program objectives in other fields of study.

\section{References}

Ali, A., \& Kohun, F. (2007). Dealing with social isolation to minimize doctoral attrition - A four stage framework. International Journal of Doctoral Studies, 2, 33-49.

Assunção, M. D., Calheiros, R. N., Bianchi, S., Netto, M. A., \& Buyya, R. (2015). Big data computing and clouds: Trends and future directions. Journal of Parallel \& Distributed Computing, 79/80, 3-15. doi:10.1016/j.jpdc.2014.08.003

Baesens, B., Bapna, R., Marsden, J. R., Vanthienen, J., \& Zhao, J. L. (2016). Transformational issues of big data and analytics in networked business. MIS Quarterly, 40(4), 807-818.

Benjamins, W. R. (2014). Big data: From hype to reality? Proceedings of the 4th International Conference on Web Intelligence, Mining and Semantics, 2:1-2:2.

Bhadani, A., \& Jothimani, D. (2016), Big data: Challenges, opportunities and realities, In Singh, M.K., \& Kumar, D.G. (Eds.), Effective Big Data Management and Opportunities for Implementation (pp. 1-24), Pennsylvania, USA: IGI Global.

Bureau of Consumer Protection (2016). FTC report provides recommendations to business on growing use of big data. Federal Trade Commission. Retrieved from 
https://www.ftc.gov/news-events/press-releases/2016/01/ftc-report-providesrecommendations-business-growing-use-big-data

Buzikashvili, N. (2007). Sliding window technique for the web log analysis. Proceedings of the 16th international conference on World Wide Web, 1213-1214.

Carlberg, C. (2018). Statistical analysis, Microsoft Excel 2016. Indianapolis, IN: QUE Publishing.

Chen, H., Chiang, R., \& Storey, V. C. (2012). Business intelligence and analytics: From big data to big impact. MIS Quarterly, 36(4), 1165-1188.

Chiang, R. L., Goes, P., \& Stohr, E., A. (2012). Business intelligence and analytics education, and program development: A unique opportunity for the information systems discipline. ACM Transactions on Management Information Systems, 3(3), Article 12.

Choi, H. Y., Chun, S. G., \& Dalsang, C. (2017). An explanatory study on the business analytics program in the U.S. universities. Issues in Information Systems, 18(2), 1-8.

Christozov, D. (2017). Business analytics as a tool to transforming information into an informing system: The case of the on-line course registration system. Informing Science: The International Journal of and Emerging Discipline, 20(1), 167-178.

Clarke, V., \& Braun, V.(2013). Teaching thematic analysis: Overcoming challenges and developing strategies for effective learning. The Psychologist, 26(2), 120-123.

Connolly, T., \& Begg, C. (2010). Database systems, a practical approrach to design, implementation, and management. Boston, MA: Addison Wesley.

Corsini, P., \& Marcelloni, F. (2006). A fuzzy system for profiling web portal users from web access log. Journal of Intelligent \& Fuzzy Systems, 17, 503-516.

Cuzzocrea, A., Song, I.-Y., \& Davis, K. C. (2011). Analytics over large-scale multidimensional data: The big data revolution! Proceedings of the 14th ACM International Workshop on Data Warehousing and OLAP, 101-104.

Das, R., \& Turkoglu, I. (2009). Creating meaningful data from web logs for improving the impressiveness of a website by using path analysis method. Expert Systems with Applications, 36(3), 6635-6644.

Data Processing (2012). In Merriam-Webster.com. Retrieved from http:/www.merriamwebster.com/dictionary/dataprocessing

Davenport (2006, January). Competing on analytics. Harvard Business Review, 84(1). 98-107.

Fowler, B., Walker, H., Williams, J., \& McDonald, D. (2015). Integrating NoSQL in the classroom. Proceedings of the 2015 Southern AIS Conference, 1-5. Retrieved from http://aisel.aisnet.org/sais2015/25

Fry, J. P., \& Sibley, E. K. (1976). Evolution of data-dase management systems. ACM Computing Surveys, 8(1), 7-42. 
Gandomie, A., \& Haider, M. (2015). Beyond the hype: Big data concepts, methods, and analytics. International Journal of Information Management, 35, 137-144.

Gupta, B., Goul, M., \& Dinter, B. (2015). Business intelligence and big data in higher education: status of a multi-year model curriculum development effort for business school undergraduates, MS graduates, and MBAs. Communications of the Association for Information Systems, 36(23), 449-476. Retrieved from http://aisel.aisnet.org/ cais/vol36/iss $1 / 23$

Hashem, I., Yaqoob, I., Anuar, N., Mokhtar, S., \& Gani, A. (2015). The rise of "big data" on cloud computing: Review and open research issues. Information Systems, 47(1), 98-115.

Krathwohl, D. (2002). A revision of bloom's taxonomy: An overview. Theory Into Practice, $41(4), 212-218$.

Khan, M., Huang, Z., Li, M., Taylor, G. A., Ashton, P. M., \& Khan, M. (2017). Optimizing hadoop performance for big data analytics in smart grid. Mathematical Problems in Engineering, 2017, 1-11. doi:10.1155/2017/2198262

Lim, E. P., Chen, H., \& Chen, G. (2013). Business intelligence and analytics: Research directions. ACM Transactions on Management Information Systems, 3(4), 1-10.

Mahapatra, T., Gerostathopoulos, I., \& Prehofer, C. (2016). Towards integration of big data analytics in Internet of Things mashup tools. Proceedings of the Seventh International Workshop on the Web of Things, 11-16.

McAfee, A., Brynjolfsson, E., Davenport, T. H., Patil, D. J., \& Barton, D. (2012). Big data: The management revolution. Harvard Business Review, 90(10), 60-68.

Mills, R. J., Chudoba, K. M., \& Olsen, D. H. (2016). IS programs responding to industry demands for data scientists: A comparison between 2011 - 2016. Journal of Information Systems Education, 27(2), 131-140.

Ong, V. K. (2016). Business intelligence and big data analytics for higher education: Cases from UK higher education institutions. Information Engineering Express, 2(1) 65-75.

Patel, K., Sundararajan, S., Marangos, C., \& Zimmers, E. W. (2016). Discovering hidden connections with big data. Industrial Engineer, 48(4), 37-42.

Phillips-Wren, G., Iyer, L. S; Kulkarni, U., \& Ariyachandra, T. (2015). Business analytics in the context of big data: A roadmap for research. Communications of the Association for Information Systems, 37(23), 448-472.

Polanka, S. (2013). Big data, little numbers: Sources for ebook statistics. Online Searcher, 71-73.

Rahm, E. (2016). Big data analytics. Information Technology, 58(4) 155-156.

Royster, S. (2013). Working with big data. Occupational Outlook Quarterly, 1, 2-9.

Russom, P. (2011). Big data analytics. TDWI Best Practices Report, 2011(4).

Sitton, J. V. (2016). Analytics is for everyone. Information Management Journal, 50(2), 44-45. 
Smith, D., \& Ali, A. (2014). Analyzing computer programming job trend using web data mining. Issues in Informing Science and Information Technology, 11(1), 203 - 214.

Sobhi, M. S., \& Son, B. G. (2010). Content analysis of OR job advertisements to infer required skills. Journal of Operational Research, 61(9), 1315-1327.

Verma, N. (2016). Towards re-orienting the big data rhetoric. Proceedings of the 19th International Conference on Supporting Group Work, 505-508.

Verma, N., \& Voida, A. (2016). Mythologies of business intelligence. Proceedings of the 19th International Conference on Supporting Group Work, 2341-2347).

Watson, H. J. (2014). Tutorial: Big data analytics: Concepts, technologies, and applications. Communications of the Association for Information Systems, 34(65), 1247-1268.

Wixom, B., Aruyachanrdra, T., Goul, M., Gray, P., \& Kulkarni, U. (2011). The current state of business intelligence in academia. Communication of the Association for Information Systems, 29(16), 300-313.

\section{Authors' Biographies}

Azad Ali, D.Sc., Professor of Information Technology at Eberly College of Business - Indiana University of Pennsylvania has 34 years of combined experience in areas of financial and information systems. He holds a bachelor degree in Business Administration from the University of Baghdad, an M.B.A. from Indiana University of Pennsylvania, an M.P.A. from the University of Pittsburgh, and a Doctorate of Science in Communications and Information Systems from Robert Morris University. Dr. Ali's research interests include service learning projects, web design tools, dealing with isolation in doctoral programs, and curriculum.

David T. Smith, Ph.D., Professor of Computer Science - Indiana University of Pennsylvania has 17 years' experience in academia and 21 years of industry experience in database systems, computer language development, and other systems programming. He holds a bachelor degree in Physics and Mathematics Education from Indiana University of Pennsylvania, an M.S. in Computer Science from University of Central Florida, and a Ph.D. in Computer Science from Nova Southeastern University. Dr. Smith is active in consultancy and has research interests in artificial intelligence, distributed object computing, data mining, and software engineering. 